\title{
Callus Induction and Plantlet Regeneration in Orthosiphon aristatus (Blume) Miq.-A Potent Medicinal Herb
}

\author{
Nissar Ahmad Reshi", M S Sudarshana \& N Rajashekar \\ Plant Tissue Culture Lab., Department of Studies in Botany, University of Mysore, Mysore, Karnataka, India.
}

\begin{abstract}
An efficient protocol was devised for rapid callus induction and plantlet regeneration from the leaves of Orthosiphon aristatus. For callus induction, auxins such as 2, 4-D, IAA, NAA alone and in combination with cytokinin BAP were used. The most effective medium for callus induction and shoot regeneration was $M S$ medium fortified with $8 \mathrm{mg} / \mathrm{l} B A P$ and $2 \mathrm{mg} / \mathrm{NAA}$, on which multiple shoots were obtained after 15 days of callus induction. All the in vitro raised shoots with length of $3-5 \mathrm{~cm}$ were transferred to rooting medium supplemented with different concentrations of IBA. The best rooting response was observed on half strength $M S$ liquid medium supplemented with $3 \mathrm{mg} / \mathrm{I} I B A$. The established plantlets obtained were subjected to hardening and acclimatisation by transferring to polycups containing sterile soil for 3-4 weeks and then to the field, where $85 \%$ survived to maturity.
\end{abstract}

Key words: Orthosiphon aristatus, leaf, Callus induction, plant regeneration, acclimatization.

\section{Introduction}

Orthosiphon aristatus (Blume) Miq.\{Syn. O. grandiflorus Bold., O. staminus Benth.\}, a popular medicinal herb in South East Asia belongs to the family Lamiaceae. It is commonly called as Kidney Tea Plant, Cat's Whiskers and Java-Tea. It grows well in moist soil and can be found in both temperate and tropical gardens. It is generally propagated vegetatively by stem cuttings. Orthosiphon aristatus, also an ornamental plant has considerable efficacy in treating various diseases. According to traditional phytotherapy, Orthosiphon tea is used for removing uric acid stones from the kidney. It also exhibits Hypoglyceamic activity (Mariam et al., 1996 [1]) and the plant is also used to treat hepato-renal syndrome (Shantanova et al., 1997 [2]) and renal ischaemia (Nikolaev et al., 1996 [3]). Its leaves have been introduced to Europe and Japan as a health tea that possess diuretic activity (Englert and Harnischfeger, 1991 [4]; Masuda et al., 1992 [5]; Beaux et al., 1999 [6]). The $\mathrm{MeOH}$ extract of aerial parts of this plant have been to found exhibit cytotoxic activity against colon cancer cells (Stampoulis et al., 1999 [7]). Two new pimarane type diterpenes, neoorthosiphols A and B have been isolated that exhibit suppressive effect on rat thoracic aorta (Ohasi et al., 2000 [8]). The accumulation of a phenolic compound called rosmarinic acid was reported in the cell cultures of Orthosiphon aristatus (Sumaryonon et al., 1991[9]). The medicinal potential of the leaves is attributed to the presence of a bitter glycoside called Orthosiphon, present in them (Wealth of India, 1996 [10]). For commercial exploitation, the flowers and the floral buds of $O$. aristatus are usually removed to enhance the quality of active constituent in the leaves. This practice consequently hinders the seed setting and subsequent utilisation of plant for conventional methods of propagation. In addition, poor germination potential of seeds also hinders the cultivation of this species. $O$. aristatus is variably distributed and very rare in the field and the conservation of this species is needed to ensure its sustainable utilisation (Rajendran et al., 2001 [11]).

The conventional propagation method is plagued with problems of scanty and delayed rooting of seedlings and the vegetative cuttings can hardly fulfil the demand of the market. Therefore, there is an urgent need to apply non-conventional methods for future commercial supply of Orthosiphon aristatus. Rapid multiplication by tissue culture could be an alternative method for mass propagation of the plant. In the present study, we report on the rapid propagation of Orthosiphon aristatus using young leaves and field establishment of the plant after acclimatization.

\section{Materials and Methods}

Orthosiphon aristatus plants were collected from the Western Ghats of Tamil Nadu, India. The plants were maintained in the garden of Department of Botany, University of Mysore. Young leaves were collected $(1.5-3 \mathrm{~cm})$ and washed well under running tap water for 15 minutes. The leaves were surface sterilised with mild phytotoxic liquid detergent (2\% Laboline, Qualiggens, India) stirred for 2 minutes and then washed with distilled water. Following this, leaves were dipped in systemic fungicide solution of $1 \%$ Bevistin for 2 minutes. Further leaves were dipped in 70\% alcohol for about 3-4 seconds and washed with sterile double distilled water followed by surface sterilization using $0.01 \%$ mercuric chloride for 4 minutes. The leaves were then washed 3 times with sterile double distilled water and finally cut into small pieces, 1 square $\mathrm{cm}$ and trimmed the margins of leaves inside laminar airflow. The sterilized and trimmed leaf explants were inoculated on M S medium with 
$3 \%$ sucrose and gelled with $0.8 \%$ agar supplemented with various concentrations of auxins such as 2,4-D, IAA, NAA in combination with cytokinin BAP. The $\mathrm{pH}$ of the medium was adjusted to 5.8 before gelling with agar and autoclaved for 20 minutes at $121^{\circ} \mathrm{C}$ for 15 minutes.

The in vitro culture were maintained at $26 \pm 2{ }^{\circ} \mathrm{C}$ and $60-70 \%$ relative humidity, light intensity was 3000 Lux with the photoperiod of 18 hours day light and 6 hours dark. In vitro differentiated shoots were excised and transferred to half strength liquid MS medium for rooting, supplemented with various concentrations of IBA.

\section{Results}

Preliminary study was conducted in order to standardise suitable medium for callus induction and regeneration of plantlets. Callus induction was observed on MS medium supplemented with different concentrations of auxins such as 2, 4-D, IAA and NAA in combination with cytokinin BAP. Callus was initiated along the cut portions after 8-10 days of inoculation; initially leaf foldings were observed (Table 1).

After the two weeks of callus induction, shoot initiation was noticed prominently in medium supplemented with $8 \mathrm{mg} / \mathrm{l}$ BAP and $2 \mathrm{mg} / \mathrm{l}$ IAA. Highest number of multiple shoots $(12 \pm 0.17)$ was recorded with $8 \mathrm{mg} / \mathrm{l} \mathrm{BAP}$ and $2 \mathrm{mg} / \mathrm{l}$ NAA followed by $8 \pm 0.15$ number of shoots with $8 \mathrm{mg} / \mathrm{l} \mathrm{BAP}$ and $2 \mathrm{mg} / \mathrm{l}$ (Table 1 ).

Table 1.Effect of BAP in combination with 2, 4-D, IAA and NAA on callus induction and shoot regeneration

\begin{tabular}{|c|c|c|c|}
\hline \multicolumn{2}{|c|}{ Concentration $\mathrm{mg} / \mathrm{l}$} & Intensity of callus formation & Mean number of shoot \\
\hline BAP & 2,4-D & & \\
\hline 2 & 1 & ++ & NR \\
\hline 4 & 1.5 & +++ & NR \\
\hline 8 & 2 & +++ & NR \\
\hline BAP & IAA & & \\
\hline 2 & 1 & ++ & NR \\
\hline 4 & 1.5 & +++ & $4 \pm 0.31$ \\
\hline 8 & 2 & +++ & $8 \pm 0.15$ \\
\hline BAP & NAA & & \\
\hline 2 & 1 & ++ & NR \\
\hline 4 & 1.5 & +++ & $5 \pm 0.25$ \\
\hline 8 & 2 & +++ & $12 \pm 0.17$ \\
\hline
\end{tabular}
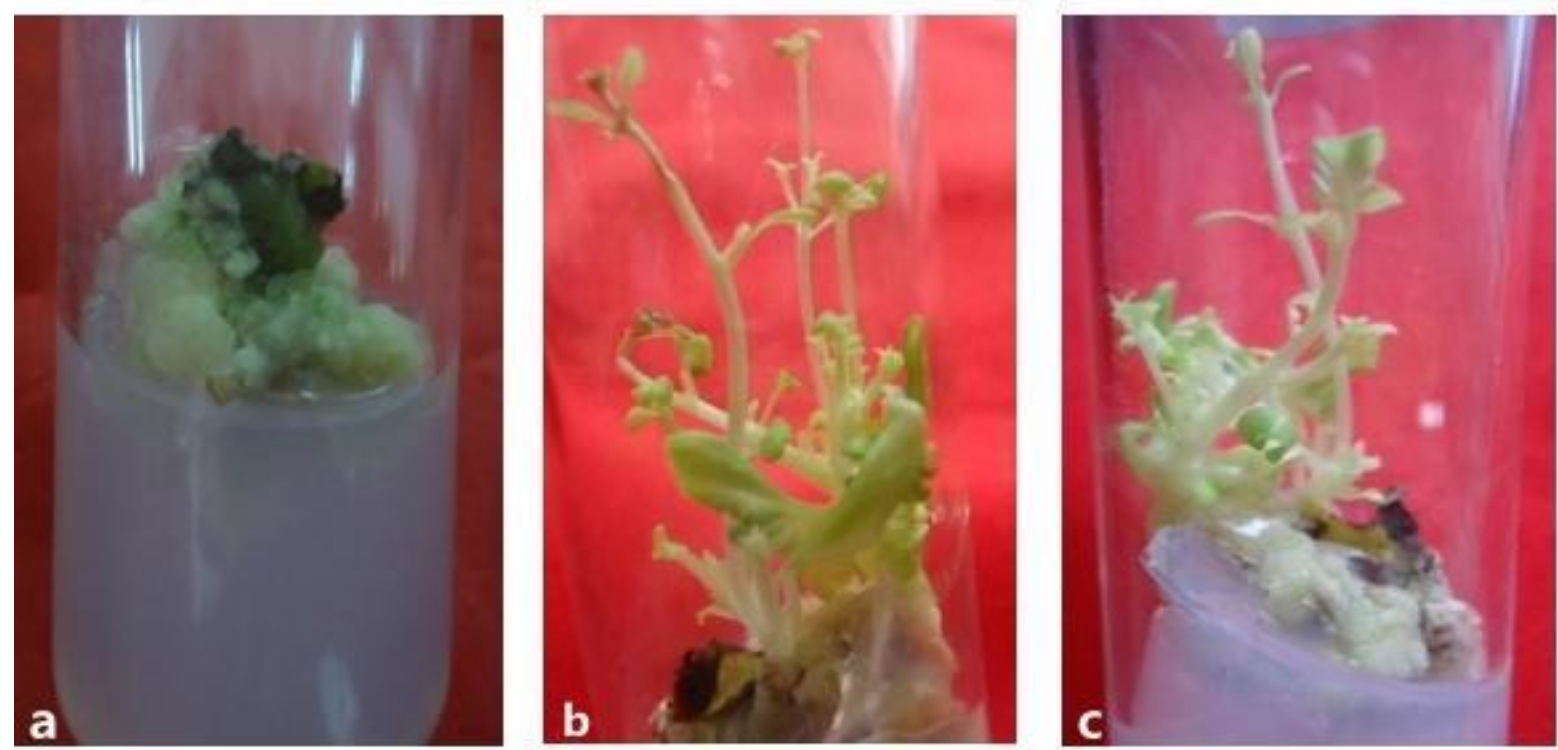

Figure.1. a. Callus formation, b \& c. Multiple shoots from callus after 2- 3 weeks of callus induction. 
The elongated shoots were subsequently rooted on half strength M S liquid medium containing different concentrations of IBA. The highest percentage of rooting was recorded when half strength MS liquid medium was supplemented with 3mg/l IBA (Table 2).

Table 2.Effect of IBA on root formation of excised shoots of Orthosiphon aristatus

\begin{tabular}{|lcc|}
\hline Concentration $\mathrm{mg} / \mathrm{l}$ & Frequency of root formation & Mean no. of roots \\
IBA & 32 & $2 \pm 0.81$ \\
1.5 & 48 & $2.7 \pm 1.33$ \\
2 & 54 & $4.7 \pm 1.88$ \\
2.5 & 71 & $7.20 \pm 2.14$ \\
3 & & \\
\hline
\end{tabular}

Similar observations were earlier reported in studies on Anisochilus Carnosus (Jeyachandran, 2004 [12]), Solanum nigrum (Narayan et al. 2010 [13]), Quisqalis indica (Poornima and Shivamurthy, 2005 [14]). Well rooted plantlets were taken out from culture tubes and transferred to polycups containing soil + vermiculite in 1:1 ratio for hardening. Finally the hardened plantlets were transferred to field conditions for maximum survivability.
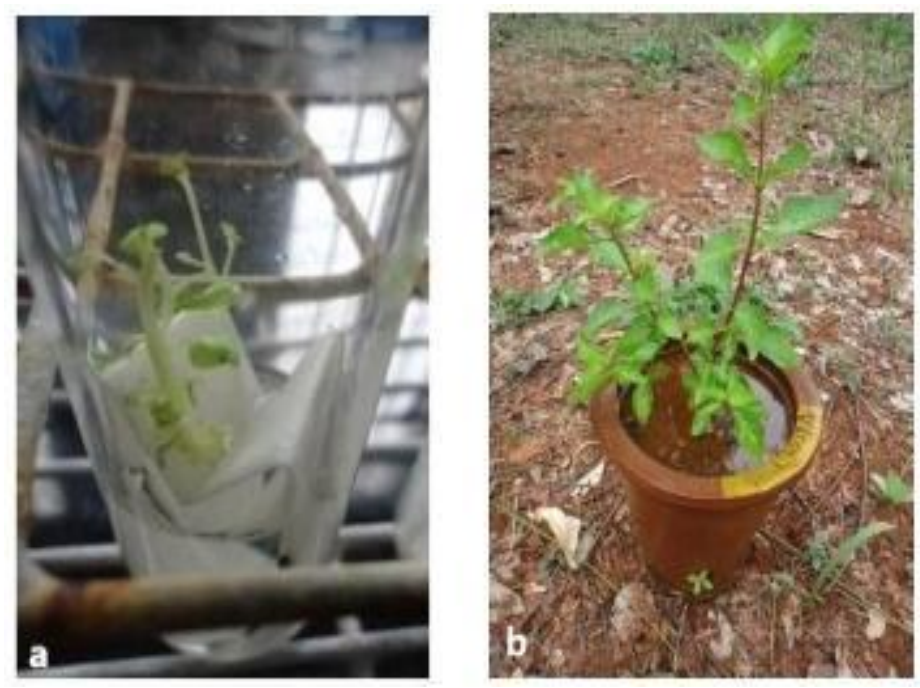

Figure.2. a) Excised shoots transferred for rooting, b) Plantlet in field conditions.

\section{Conclusion}

The present study describes the standardized protocol for callus induction and indirect plant regeneration from the leaves of $O$. aristatus, which may be useful in future research for enhanced production of this valuable medicinal herb and to obtain possible somaclonal variants for its genetic improvement. Depletion of wild population can be prevented through such in vitro cultivation for commercial exploitation. NAA and BAP were found to be the most appropriate hormone combination for callusing and multiple shooting. The study provides a standard protocol to initiate callus and multiple shoots, optimization of media content and hormonal concentration that may provide desired source of pharmacologically active plant constituents through callus culture. On the basis of our experiments, the young leaf explants seems to be good starting material for micropropagation of $\mathrm{O}$. aristatus.

\section{References}

[1] A. Mariam, M. Z. Asmawi, and A. Sadikum, Hypoglyceamic activity of the aqueous extract of Orthosiphon aristatus, Fitoterapia, $67,1996,465-468$.

[2] L. N. Shantanova, S.M. Nikolaev, A. G. Mondodoev, The influence of nephrophyte preparation on the functional state of liver and kidneys during intoxication by carbon tetrachloride. Rastitel'nye-Resursy, 33, 1997, 101-109

[3] S. M. Nikolaev, A.G. Mondodoev, L. N. Skantanova, V. I. Glyzin, Pharmacotherapeutic effectiveness of nephrophyte in cases of renal ischaemia. Rastitel'nye-Resursy 32, 1996, 1117-121.

[4] J. Englert, G. Harnischfeger, Diuretic action of aqueous Orthosiphon extract in rats. Planta Med., 58, 1991, 237-238.

[5] T. Masuda, K. Masuda, N. Nakatani, Orthosiphol A, A highly oxygenated diterpene from the leaves of Orthosiphon staminus, Tetrahedron Litt. 33, 1992, 945-946. 
[6] D. Beaux, J. Fleurentin, F. Mortier, Effect of extracts of Orthosiphon staminus, Hieracium pilosella L., Sambucus nigra and Arctostaphylos uva-ursi..in rats. Phytother Res., 13, 1999, 222-225

[7] P. Stampoulis, Y. Tezuka, Q. T. Kim, I. Saika, S. Kodaka, A novel diterpene from Orthosiphon staminus. Tetrahedron Litt.,40, $1999,4239-4242$.

[8] K. Ohasi, T. Bohgaki, T. Matsubara, H. Shibuya, Indonesian medicinal plants. XXIII. Chemical structure of two new migrated pimarene type diterpenes, neoorrthosiphols $A$ and $B$, and suppressive effects on rat thoracic aorta of chemical constituents from the leaves of Orthosiphon aristatus. Chem. Pharm. Bull. 48, 2010, 433-435

[9] Wealth of India, A Dictionary of Indian raw Materials and Industrial Products, Vol. VIII , 1996, 79-89 CSIR Publications New Delhi.

[10] W. Sumaryonon, P. H. Proksch, T. Hartmann, M. Nimtz and V. Wary, Induction of rosmarinic acid accumulation in cell suspension cultures of Orthosiphon aristatus after treatment with yeast extract, Phytochemistery, 30, 1991, 3267-3271

[11] R Jeyachandran, In vitro culture root formation in Anisochilus Carnosus, J. Swamy Bot. Clubb., 21, 2004, 27-30.

[12] S. M. Rajendran, K. Chandrashekar and V. Sundersan, Ethnomedicinal lore of Seithur hills-Southern Western Ghats, Tamil Nadu, Ethnobotany, 13, 2001; 101-109.

[13] P. Narayan, B. Ranjit and K. Vijay, In vitro multiplication of important medicinal plant Solanum nigrum, Recent Research in Science and Technology,2(7), 2010, 33-35

[14] D. Poornima and G. R. Shivamurthy, Root formation in Quisqualis indica , J. Swamy Bot. Clubb., 22, 2005, 37-38 